\title{
Life-Cycle Labor-Force Participation of Married Women: Historical Evidence and Implications
}

\section{Citation}

Goldin, Claudia. 1989. Life-cycle labor-force participation of married women: Historical evidence and implications. Journal of Labor Economics 7(1): 20-47.

\section{Published Version}

http://dx.doi.org/10.1086/298197

\section{Permanent link}

http://nrs.harvard.edu/urn-3:HUL.InstRepos:2656816

\section{Terms of Use}

This article was downloaded from Harvard University's DASH repository, and is made available under the terms and conditions applicable to Other Posted Material, as set forth at http:// nrs.harvard.edu/urn-3:HUL.InstRepos:dash.current.terms-of-use\#LAA

\section{Share Your Story}

The Harvard community has made this article openly available.

Please share how this access benefits you. Submit a story.

Accessibility 


\title{
Life-Cycle Labor-Force Participation of Married Women: Historical Evidence and Implications
}

\author{
Claudia Goldin, University of Pennsylvania and \\ National Bureau of Economic Research
}

The seven-fold increase, since 1920, in the labor force participation rate of married women was not accompanied by a substantial increase in average work experience among employed married women. Two data sets giving life-cycle labor-force histories for cohorts of women born from the 1880 s to 1910 s indicate considerable (unconditional) heterogeneity in labor-force participation. Employed married women had substantial attachment to their jobs; increased participation brought in women with little prior work experience. Average work experience among cross sections of employed married women increased from 9.1 to 10.5 years over the $1930-50$ period. Implications for "wage discrimination" are discussed.

\section{Life-Cycle Labor-Force Participation}

One might have expected the seven-fold increase, since 1920, in the labor-force participation rate of married women to have been accompanied

This research has been supported by a grant from the National Science Foundation. The comments of Shelly Lundberg, Robert Margo, Paul Taubman, and the participants of workshops at the University of Chicago, Harvard University, and the University of Western Ontario are gratefully acknowledged. An earlier version of this paper was circulared as NBER Working Paper no. 1251, and the research in it was performed without knowledge of similar work for a later period by James Smith and Michael Ward.

[Journal of Labor Economics, 1989, vol. 7, no. 1]

(C) 1989 by The University of Chicago. All rights reserved.

0734-306X/89/0701-0006\$01.50 
by a substantial increase in average years of job experience. Surprising as it may seem, the data assembled here and elsewhere (Smith and Ward 1984; O'Neill 1985; Moulton 1986) suggest that average years of work experience among currently employed married women increased little over much of the period since 1920. Work experience over the life cycle provides the link between changes in labor-force participation rates and changes in years of job experience among the working population.' The greater the tendency of women to remain in the work force over the life cycle, the more increases in labor-force participation rates will depress, not increase, accumulated work experience among employed women. Using the terminology in this paper and elsewhere (Heckman and Willis 1977), the more "heterogeneous" are women with regard to labor supply, the more increases in participation will bring less experienced women into the labor force. The question, therefore, is just how heterogeneous or homogeneous is the population of women. Two data sources are used to explore the issue for women born in the period from the 1880 s to 1910 s, and the results are used to extrapolate the life cycle of work from 1900 to 1980.

The two sources contain retrospective information on cohorts considerably older than those covered by two well known panel studies, the National Longitudinal Survey (NLS) and the Panel Study on Income Dynamics (PSID). The first of the sources is contained in original schedules of a 1939 Women's Bureau bulletin (U.S. Department of Labor 1941), which I believe is the earliest retrospective information on life-cycle laborforce participation for a large sample of women. ${ }^{2}$ The second is a more familiar source, Social Security Administration records linked to the Retirement History Study (Irelan et al. 1987).

These two sources confirm for an older group of cohorts what has been found among more recent ones: a substantial fraction of married women in the labor force have a high degree of attachment to it. The schedules from the Women's Bureau bulletin, called here the 1939 Retrospective Survey, indicate that, among married women born between 1890 and 1899 and in the labor force in $1939,86 \%$ had worked more than $50 \%$ of the years since beginning work and $54 \%$ had worked more than $87 \%$ of the years since beginning work. Among similar women not in the labor force in 1939 , only $19 \%$ had worked more than $50 \%$ of the years since beginning work and just $2 \%$ had worked more than $87 \%$ of the years. The Social Security Administration records tell a similar story. Among white married

1 The labor-force participation rate gives the percentage of individuals working or seeking a job some time in the week preceding the census, or, prior to 1940 , the percentage who stated they had an occupation during the census year. (For the relationship between the two measures, see Goldin [1986].) The labor-force participation rate lacks a longitudinal dimension and does not give the proportion of the year individuals work.

2 The Women's Bureau was founded in 1920 as part of the Department of Labor. 
women born from 1906 to 1910 and in the labor force in 1953,48\% would eventually work during $90 \%$ of the years covered in the data, those from 1951 to 1969. Determinants of labor-force commitment are also analyzed to explore how a woman's initial occupation influenced her future work experience.

Estimates of years of job experience, for women employed between 1910 and 1980 and born from 1875 to 1925 , are generated from these two sources. According to the estimates, average years of work experience for cross sections of working married women increased by only $15 \%$ from 1930 to 1950 (rising from 9.1 years to 10.5 years) at the same time there were substantial increases in the labor-force participation rate of the group. Yet work experience for the entire female labor force increased at a greater rate over the first half of this century because married women expanded their share of the female labor force almost five-fold, from $10 \%$ to $47 \%$. Surveys from 1890 to 1900 report figures of 6-7 years for the work experience of employed women (Goldin and Polachek 1987), and the data from the 1939 Retrospective Survey yield a value of 10.7 years or a growth rate of about $65 \%$ from 1900 to 1940 . Data from a study by Smith and Ward (1984) indicate that years of job experience among all working women rose from 11.6 years in 1950 to 12.2 years in 1980, comparable to the less reliable estimates I produce for the period, an increase of only $5.2 \% .^{3}$

The absence of a positive relationship between the gender gap in earnings and the gender gap in labor-force participation from 1950 to 1980 has been puzzling to many. But because wages are usually calculated only for the currently employed, the steadiness in the ratio of female to male (fulltime) earnings during the period since the 1950 s may have resulted, at least in part, from rising labor-force participation rates. Further, recent evidence I have compiled indicates that the gender gap in earnings actually narrowed from 1890 to 1930 (Goldin 1987). The findings presented here on work experience are also consistent with the increase in the ratio of fermale to male (full-time) earnings from .463 in 1890 to .556 in 1930 . But the dynamic and static consequences of labor-force persistence are very different. Persistence in the labor force means that women accumulate considerable work experience and, therefore, that differences in earnings by sex at any point in time are less explicable. The implications of this study for "wage discrimination" and for changes over time in the ratio of female to male earnings are therefore opposite in nature.

The apparently anomalous findings concerning changes in labor-force participation and cumulated experience owe to the substantial fraction of

${ }^{3}$ The aggregate cross-section numbers are calculated from data in Smith and Ward $(1984$, p. 71$)$ using the :ollowing procedure. The work-experience data by age are regressed on age; estimates of work experience for various age groups are then weighted by the age distribution of employed women in each of the years. 
married women who stay in their present working state from year to year. Even though increases in the labor-force participation rate expand the pool of working women and thus raise years of experience for the entire population of women, years of job experience for the working population can remain relatively constant. Because working women tend to remain in the labor force, those drawn in as participation rates increase have fewer years of accumulated work experience than those already working. Put in other, more familiar, terms: the marginal labor-force entrant brings down the work experience of the average worker.

\section{Homogeneity and Heterogeneity of Female Labor Supply}

The labor-force participation rate is an ambiguous concept. One of, say, $40 \%$ can mean that $40 \%$ of the population is continuously in the labor force over the year, while the other $60 \%$ are always out. Alternatively it can mean that each individual is employed 21 weeks over the year $(40 \%$ $\times 52$ ). The truth will certainly lie between these two extremes. "Following Heckman and Willis (1977), call the first case that of "heterogeneity" because the population consists of two types, those currently in the labor force and those currently out, and call the second extreme case that of "homogeneity" because all individuals work the same number of weeks per year. The degree to which the population tends to one or the other will determine the accumulated work experience of currently employed women.

A population of women, all of whom are homogeneous with respect to labor supply, are defined here as having identical probabilities of being in the labor force in any year. ${ }^{6}$ Employment over the year is stochastic and is the ex post realization of a draw from an identical distribution determining when employment will occur. If homogeneity is conditional on various characteristics, such as education and husband's income, women within these groups will have identical lifetime labor supply?

4 Ben-Porath (1973) and Heckman and Willis (1977) also examine these concepts.

${ }^{5}$ The terminology becomes somewhat confusing if participation increases over the life cycle. In the first case, that of heterogeneity, women initially out of the labor force must enter and subsequently remain in. In the second case, that of homogeneity, an increase in participation means that each woman is employed more weeks during each year.

' One can also consider a group of homogeneous women as working the same number of years over their lifetime, but working them in different parts of the life cycle.

7 Throughout the discussion the notions of heterogeneity and homogeneity will be made with reference to the unconditional probabilities of being in the labor force. See Heckman and Willis (1977) for a discussion of the conditional probabilities and their reply (Heckman and Willis 1979) to Mincer and Ofek (1979) in which they discuss these concepts in unconditional terms. The conditional probabilities are relevant to interpreting parameters from labor supply equations used to estimate 
At the other extreme is the notion of heterogeneous labor supply. In this case, the population always consists of two groups, those in and those out of the labor force. The distinction is complicated by the movement of those out of the labor force to being in the labor force. Thus, if labor-force participation is unchanging with age, heterogeneous women are stayers, being either in or out of the labor force their entire lives. In general, heterogeneous women remain in or out of the labor force in a manner that must be consistent with the aggregate labor-force participation rate. ${ }^{8}$ If labor-force participation increases over the life cycle of the cohort, then entrants are drawn into the labor force from the pool of women who have rarely or never yet been employed. When cohort participation rises with age, as it has in the United States for married women, heterogeneity implies that the highest labor-force participation rate achieved by a cohort is the maximum percentage of the cohort ever to be in the labor force. Likewise, one minus this proportion represents those who have never been in the labor force.

In two highly influential papers, Jacob Mincer $(1962,1966)$ reasoned that the average labor-force participation rate for a cohort is the percentage of time a randomly selected woman in that cohort will work over her lifetime. Her life-cycle decisions, therefore, are to choose the percentage and then allocate it over time. Ben-Porath (1973) had questioned Mincer's logic in light of data in the 1960 census suggesting that women who were not in the labor market in 1960 had worked very little the decade before. "That is, even though these data do not refer to experience under static conditions, they indicate that a fair amount of current nonparticipation in the labor force represents 'permanent' nonparticipation" (p. 701).

The evidence that first prompted Ben-Porath to question the presumed notion of homogeneity was suggestive but weak. Considerably better data are now available in both the NLS and the PSID. Heckman and Willis (1977), among others, have made extensive use of these panel data to analyze the nature and determinants of life-cycle labor-force participation. While the determinants of life-cycle labor-force participation continue to be elusive, its nature has become decidedly clearer.' The two panel studies

income and substitution effects. The unconditional probabilities are relevant here to estimating years of work experience among currently employed women.

8 That is, if labor-force participation for each cohort were an increasing function of age, then those in the labor force at the start of their lives would always remain in and be joined later by others with no labor-market experience. If, on the other hand, labor-force participation were a decreasing function of age, women would exit from the labor force. A bimodal configuration would require first an exit and then an entrance of those exiting most recently.

"See Heckman and Willis (1979) for a criticism of their own "beta-logistic" procedure that assumes constant (conditional) participation probabilities over time. The data indicate, however, that these probabilities change with time, due possibly to unmeasured variables, such as fixed entry costs, or to a changed impact of certain variables, such as number of children, which they treat as constant over time. 
(NLS and PSID) have provided distributions of the actual percentage of a woman's married lifetime spent in the labor force. For cohorts born from 1922 to 1937 the distribution is not center weighted, as would be implied by the homogeneity assumption, but is vaguely $U$-shaped, having a large mass in the lowest and highest deciles.

Because these data span a period of rapidly rising labor-force participation rates, any distribution of years worked would tend toward the uniform or the fat-tailed unimodal, even if there were considerable underlying heterogeneity. ${ }^{10}$ Such heterogeneity would, under stable conditions, result in a $U$-shaped distribution. The increase in participation arises in part because prior nonparticipants are drawn into the labor market. The greater the increase in participation, the smaller the mass will be at zero years experience.

If women were identical, but there were random variation in, say, the timing of children, then all would be in the labor force the same percentage of their lifetimes, but each would vary labor-market entry and exit accordingly. Within such a world, women would have relatively high turnover, and each would not amass much job-related human capital. " Consider instead a world in which women are heterogeneous with respect to labor supply. Women in this labor force would be "stayers" and would remain in for rather long durations. Those who joined the labor force early in life should, if unconstrained, choose an occupation and a training path more like that of a man, whose life-cycle labor-force participation is generally uninterrupted. When the aggregate female labor-force participation rate is increasing over time, women just entering the labor force would come from a pool of previous nonparticipants, and their choice of occupation would depend on their remaining time in the labor force.

Consider two worlds having identical participation rates by age but in one all women are homogeneous and in the other they are heterogeneous. Extreme differences in the accumulated experience of women could arise

${ }^{10}$ If women are homogeneous, all have an identical value for the percentage of their lifetime spent in the labor force, and the density function will have the entire mass at that percentage, generally somewhere between zero and one. If, instead, the population of women were heterogeneous and labor-force participation for the cohort were neither rising nor falling with age, the distribution of years in the labor force for a cohort will have one mass at zero and another at one. The distribution of individuals between these two masses would then depend entirely on how the participation rate changes with age. If the labor-force participation rate were rising with age for the cohort, the density function would have a mass at zero and then decrease. Therefore, even if there were considerable underlying heterogeneity, rising cohort participation rates with age would cause the distribution of years worked to be vaguely uniform. If some of the population were homogeneous, a mixture of these two distributions would be unimodal and fat-tailed.

"Note that, in the case of homogeneity, the average continuous employment spell over $n$ years is the sum of the series $\left\{L^{\prime}\right\}, t=0, \ldots, n$, which equals $[1 /(1-L)]$ when $n$ is very large and where $L=$ the labor force participation rate and is unchanging with age. 
between these two worlds. In the steady state, the world of heterogeneous women would have the greatest degree of accumulated labor-force experience of working women, a higher average wage for currently working women, and an occupational distribution most resembling that of men, ceteris paribus. The relationships between expected years in the labor force and occupational choice and between accumulated experience and earnings underscore the importance of determining the degree to which the population of women is heterogeneous or homogeneous with respect to laborforce participation.

\section{Quantitative Evidence on Life-Cycle Labor-Force Participation of Married Women}

Two types of data provide useful evidence on life-cycle labor-force participation: longitudinal data from panel studies, in which individuals are reinterviewed over a considerable period of time, and retrospective surveys of work experience gathered at one point in time. Longitudinal data, such as the NLS and the PSID, are the most reliable and accurate, but these two data sets cover only the period since 1967 longitudinally (although the period before 1967 is covered retrospectively) and include only women born since about 1923, those 30-44 years old in 1967.

Also of the panel form are the rich data files of the Social Security Administration (see Ruggles and Ruggles 1977) that have been linked to three data sets: the Current Population Survey, 1973; the Retirement History Study, 1969-74; and Internal Revenue data. ${ }^{12}$ Each of these data sets excludes by necessity certain occupations and employers not covered by social security at the time. Domestic service and agricultural workers were covered by Social Security beginning only in 1954, although restricting the analysis to white women minimizes the potential bias. ${ }^{13}$

Retrospective answers to questions on work experience are a second type of data giving information on life-cycle labor-force participation and are particularly useful when they include work histories of both those currently at work and those not currently working. A thorough investigation of various data sets reveals that the earliest microlevel evidence on life-cycle female labor-force participation is contained in a somewhat ob-

${ }^{12}$ These three files are also known as the exact match samples because individuals in these data sets have been precisely matched by social security number.

${ }^{13} \mathrm{~A}$ more severe problem arises in the case of government employees, particularly teachers. Various state governments joined the federal social security program in 1951 when amendments to the original Social Security Act made public employees eligible for coverage, and other state and local governments joined when the act was changed again in 1954 and 1956 . Approximately $75 \%$ of all teachers were covered by social security in 1979, but it cannot be determined how coverage of all public employees has changed over time with regard to sex and occupation. 
scure document: U.S. Department of Labor, Women's Bureau, "Women Workers in Their Family Environment," Women's Bureau Bulletin no. 183 (1941).

The original data in the bulletin pertain to working and nonworking women interviewed in Cleveland in 1939. ${ }^{14}$ The Women's Bureau attempted to ensure that this was a probability sample, in terms of occupation, age, and industry, and chose Cleveland as a representative city with regard to the proportion of its married female population employed in 1940, nearing 20 percent at the lower age brackets and just below 15 percent above age 35. Because these data contain unique information and the printed tabulations have numerous ambiguities, the originals were located in the $\mathrm{Na}$ tional Archives and computerized. ${ }^{15}$ The discussion below is based on this data file, called here the 1939 Retrospective Survey. ${ }^{16}$

The original schedules located in the archives are in two parts. One contains data on over 2,800 women (including 742 currently married women) who were working in 1939 , and the other contains the schedules for 532 married women who were not working in 1939 but who had worked some time in the past. Information for working women was coded and tabulated by the Women's Bureau in 1940, but the original schedules were then destroyed. Index cards containing the codes were preserved, and the codes, fortunately, were recorded in a set of auxiliary documents in the collection. Because the Women's Bureau was primarily interested in working women, the data for those not currently working were not coded, but the original schedules for this group exist. A somewhat more detailed set of variables can therefore be obtained for the women not currently at work in 1939. Complicating the analysis a bit further is that the Women's Bureau had coded work time for currently working women in 5-year intervals (e.g., 5-10 years of employment in the same occupation, $10-15$ years in two similar occupations), and therefore precise gaps in employment cannot be located for these women. But these are minor shortcomings in this unique set of data.

The distributions of the percentage of years that women spent in the

${ }^{14}$ Various Utah cities are also included in the survey but were not sampled because of their atypicality.

is The bulletin does not distinguish between tabulations of the entire population and those of currently working women; women with continuous work experience are not included in the tabulation of work breaks; and the number of married women in the sample changes from table to table. In short, it is not possible to infer from the tables alone the population at risk of a particular event.

${ }^{16}$ The original documents are in the National Archives, Record Group No. 86, boxes 446-50. Information is included on: marital status, age, foreign birth, education, complete retrospective work histories, first occupation, last occupation, date at which work began, and, frequently, dates of marriage(s) and pregnancy(ies). U.S. Department of Labor (1941) contains a detailed description of the survey. 
labor force since beginning work are given in table 1, part A. ${ }^{17}$ The data are arrayed by birth cohort, and the focus will be primarily on the older women, whose life cycles were already near completion in 1939 . The sample contains data for about 800 women older than 29 years of age and is from a relatively homogeneous group of white urban, married women with husbands living at home in 1939 .

The substantive finding of table 1 is that married women currently at work in 1939 had considerably different labor-market histories than those not at work in 1939. For women $40-49$ years old in $1939,54 \%$ had participated in the labor force more than $87 \%$ of the time since they first worked. Although the number drops to $41 \%$ for the oldest age group (5059 years old), $51 \%$ of them had been in the labor force more than $75 \%$ of the time since they had begun work.

The data for women not currently working (in 1939) are in stark contrast. The distributions of lifetime work are exact opposites of those for currently working women. Among women 40-49 years old in 1939, 49\% had worked less than $25 \%$ of the time since they had their first job and only $2 \%$ had worked more than $87 \%$ of the time. For those $50-59$ years old the percentage who worked less than $25 \%$ of the time is $65 \%$. Further, because the data include by necessity work prior to marriage, differences after marriage between these two groups would be even greater. It seems clear in using this particular measure of life-cycle labor-force participation that women currently in the labor force had worked a substantial percentage of their years since their first employment, but that those who were not currently in the labor market had been infrequent participants all of their lives. These findings are similar to those first noted by Ben-Porath (1973) and later by Heckman and Willis $(1977,1979)$, but span a far earlier group of cohorts.

Some of the stability in labor-force participation apparent in the sample may have been the product of the Depression. Women who had jobs in the 1930 s may have tried to maintain them because of unemployment risk, and those who entered the Depression without jobs stood a poor chance of becoming employed. But the oldest cohorts in the sample were recounting labor-market experiences extending well before the Depression, and their life cycles were only in part affected by the Depression years.

${ }^{17}$ The experience variable for those currently working differs somewhat from that for those not currently working. For those working in 1939, the original surveys were destroyed and codes constructed by the Women's Bureau to summarize the information are used. The codes group work experience by years and by job continuity. The midpoints of the groups are used, e.g. 7.5 years for 5-10 years, unless the value is inconsistent with other information, such as whether the individual stated she worked continuously since work began. For the sample of those not currently at work, a precise measure of years of employment is available from the original schedules. 
Table 1

Life-Cycle Labor-Force Participation of Married Women at Work and Not at Work in 1939

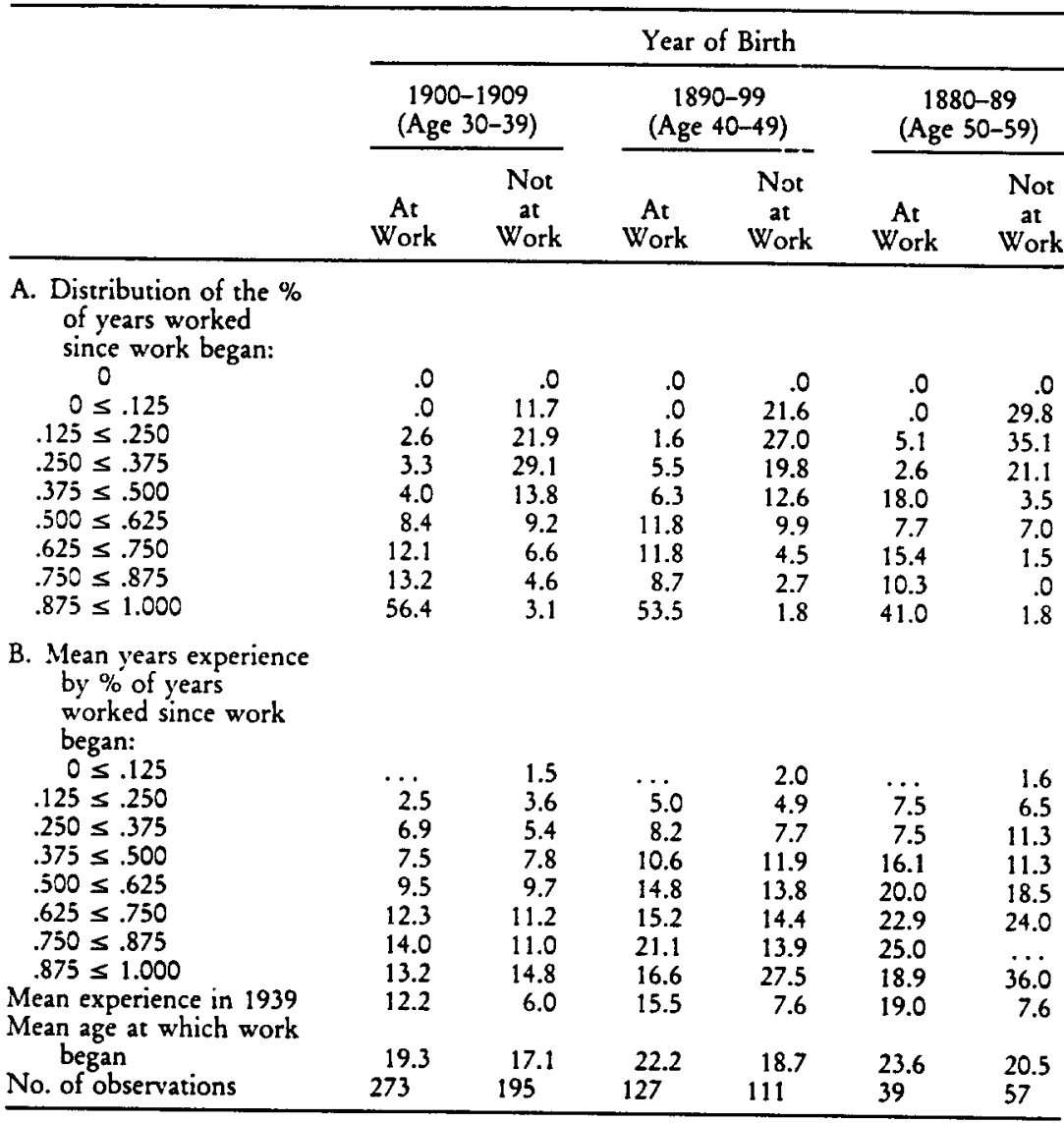

SOURCF..-1939 Retrospective Survey. See n. 16 above.

NOTE. - Married women include only married n'ith spouse present. All intervals exclude lower bound and include upper bound. Means for the age at which work began and average experience also include observations having missing variables for the percent of time worked since work began. The small number of observations in the oldest age group implies that means within that age group by percent are measured imprecisely. Ellipses (. . .) indicate there are no observations in the cell.

Further, the Depression could bias work histories away from persistence because the Depression led to the firing of many workers, particularly married women. ${ }^{18}$

The lifetime participation measure used in table 1 , the percentage of years worked since beginning work, was dictated by the surviving infor-

${ }^{18}$ In the Depression, many firms instituted or extended policies, known as "marriage bars," that required women be fired when they married and married women not be hired. See Goldin (1988, in press). 
mation in the records. A better measure for comparison with other studies would be the extent of participation since the time of marriage. Such information exists for many of the nonparticipants but not for those working in 1939. All of the (current) nonparticipants had been in the labor force sometime in the past, by the design of the survey, and table 2, part B, summarizes their work histories by age. Most, somewhere between $50 \%$ and $60 \%$, exited with marriage and did not return to work prior to 1940 , and only about $30 \%$ worked both before and after marriage. A small percentage indicated they worked only after marriage, however, some, particularly in the older age groups, probably worked before marriage but failed to recall such distant events. ${ }^{19}$ About $10 \%$ did not indicate when they married, and, therefore, the relationship between marital status transitions and the timing of labor force exit could not be ascertained.

Further computations indicate that among those 40-49 years old in 1939 more than $80 \%$ exited the labor force at the precise time of marriage, although some eventually returned. ${ }^{20}$ Therefore, even though average years of work experience among employed married women was substantial, the vast majority of all single women exited the labor force at marriage. Employers may have been unable to discern who would persist in the labor force and may have restricted job opportunities of all women.

Gaps in work experience for those currently working cannot be precisely located in these data. Part $A$ of table 2 summarizes the information that does exist on the continuity of labor-force involvement for this group. About one-third, independent of age, had remained in a similar occupation without a break in labor-force participation since beginning work. Another third had some break in experience but remained in a similar occupation, and the remaining third experienced both a breat in experience and a change in occupation.

Labor-market work began not long after school completion for most of the age groups, but for the oldest age group, 50-59 years, initial labor-

19 The Women's Bureau apparently believed the data on the age at which work began. "In Cleveland, where $8 \%$ of today's women workers were not even graduated from the grammar grades, not far from half (43\%) of these women did not go to work until 18 years of age or older, and a noticeable proportion not until after 25 years" (p. 3).

${ }_{20}$ Among the 111 women (40-49 years old) not at work in 1939, 62.1\% dropped out at marriage, $4.5 \%$ worked only after marriage, and $33.3 \%$ worked before and after marriage (see table 2), of whom $86 \%$ dropped out at marriage but later reentered. Therefore, of those not working in 1939 but who worked when single, (101/ 106) $=95 \%$ dropped out at the time of marriage. Precise gaps in employment are not available for the 123 who were working in 1939 , but at a minimum none left work at marriage. To get the population average, one must weight by the laborforce participation rate, or about $15 \%$ for those at work in 1939 . Thus, at a minimum $(.85 \times .95)=80.8 \%$ of the $40-49$ year old group who worked when single dropped out of the labor force at the precise time of marriage. The upper-bound figure is $91.1 \%$. 


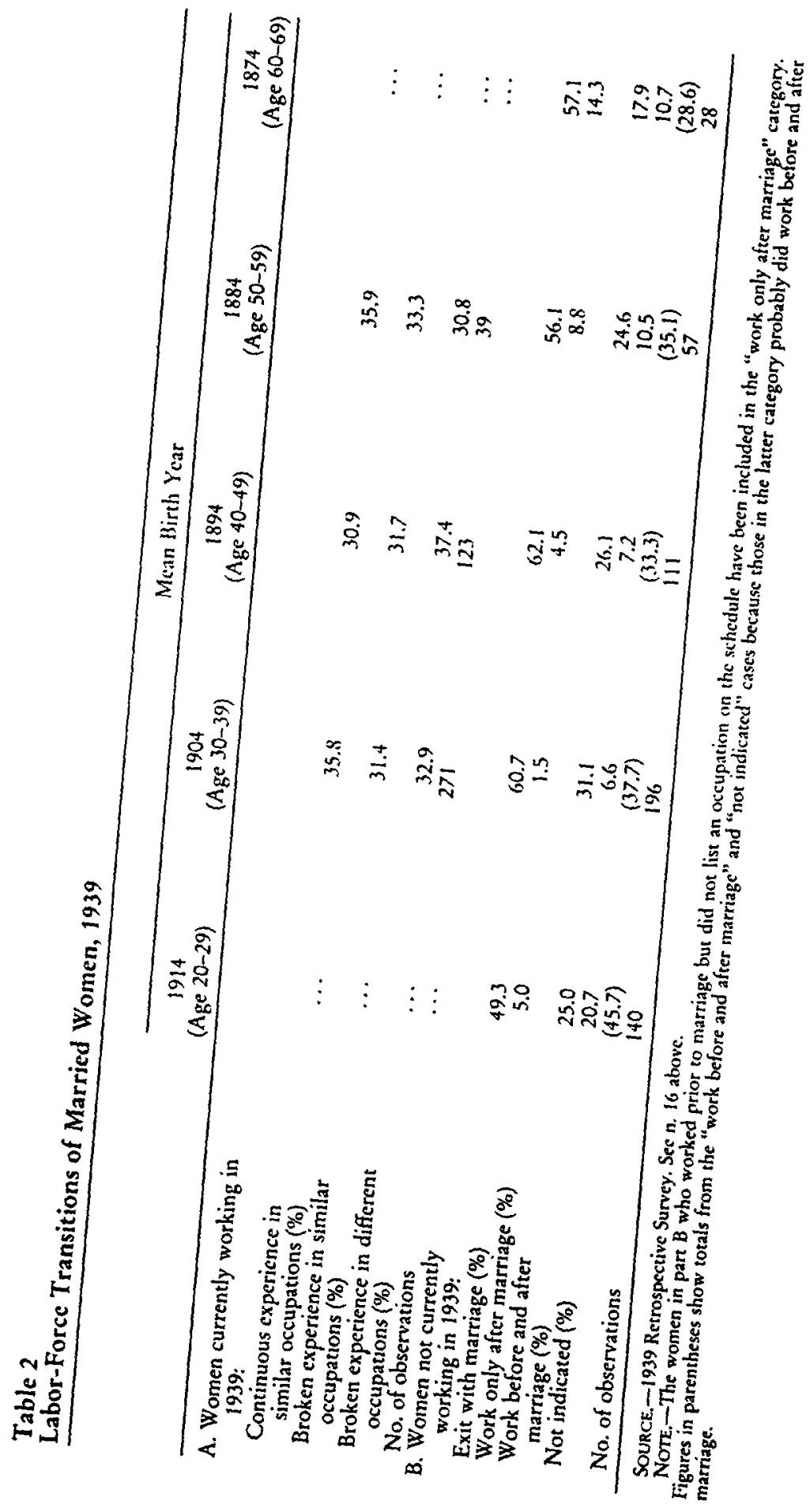


market contact was reported to have occurred at a fairly late age, indicating that work must have begun after marriage for many of these women. Alternatively, and as mentioned above, the first instance of labor-market contact may have been forgotten. To correct for possible biases due to misreporting the year at which work began, distributions similar to those in table 1 (not included here) were constructed only for women whose reported age at first employment was less than 30 years old. The results do not change substantially for women less than 50 years old. But women in the oldest age group showed a far lower percentage, working more than $87 \%$ of their years since beginning work, although $54 \%$ still worked more than $63 \%$ of these years.

A somewhat different measure of lifetime labor-force participation, the percentage of time worked since marriage, is the statistic most commonly used to explore the life-cycle labor-force participation of married women, presumably because women spend most of their postschooling, unmarried years in the labor force. Including years before marriage flattens out the distribution of years worked, causing it to be more uniform. Thus the markedly nonuniform distributions in table 1, part A for life-cycle laborforce participation imply that those for only the years since marriage would be even more skewed.

What accounts for the different life cycles of the participants and nonparticipants, or, in the terms of the previous section, what accounts for the degree of heterogeneity observed? The analysis is constrained by the variables in the 1939 Retrospective Survey, which exclude wealth, husband's income, and number of children. Yet many predetermined characteristics, such as education and first occupation, can be included.

Pooling the two data sets, that of workers and nonworkers, allows the estimation of equations to explain work status and the percentage of years worked since work began. Table 3 gives two equations, one for WORK ( 1 = works in 1939) estimated as a logit by maximum likelihood (MLE) and another for PERCENT = [experience $/($ age - age work began $)]$ estimated using a logistic transformation. Current workers had more education than nonworkers, were younger, began work at an older age, and were less likely to have begun work in a manufacturing job. Most of these results are not surprising. What is, however, is the lasting impact of a woman's first occupation independent of years of schooling and the age at work entry. Women who began in a manufacturing job had a reduced probability of later work of nine percentage points $(.2 \times .8 \times-.533)$, assuming a participation rate of $20 \%$.

The regression explaining PERCENT, the percentage of time worked since work began, was estimated across two samples, the original pooled sample and a subsample of women whose first work experience occurred prior to age 30 . The results do not differ markedly, and only those from the full sample are given. The important finding again concerns the role 
Table 3

Explaining Work Status and Life-Cycle Labor-Force Participation of Married White Women in 1939

\begin{tabular}{|c|c|c|}
\hline & $\begin{array}{l}\text { WORK } \\
(1=\text { Works in 1939) } \\
\text { Logit Estimation } \\
(\beta)\end{array}$ & $\begin{array}{c}\text { PERCENT* } \\
\text { [Experience/(Age - Age Work Began)] } \\
\text { Logit Estimation } \\
(\beta)\end{array}$ \\
\hline Constant & $\begin{array}{r}-3.864 \\
(2.73)\end{array}$ & $\begin{array}{l}1.712 \\
(1.09)\end{array}$ \\
\hline Age & $\begin{array}{c}.073 \\
(1.53)\end{array}$ & $\begin{array}{r}.133 \\
(2.38)\end{array}$ \\
\hline $\mathrm{Age}^{2} \times 10^{-2}$ & $\begin{array}{l}-.166 \\
(2.71)\end{array}$ & $\begin{array}{l}-.371 \\
(4.72)\end{array}$ \\
\hline Age work began & $\begin{array}{c}.104 \\
(9.13)\end{array}$ & $\begin{array}{r}.157 \\
(11.64)\end{array}$ \\
\hline Education & $\begin{array}{r}.375 \\
(1.95)\end{array}$ & $\begin{array}{r}.277 \\
(1.11)\end{array}$ \\
\hline Education $^{2} \times 10^{-2}$ & $\begin{array}{c}-1.658 \\
(1.69)\end{array}$ & $\begin{array}{r}-1.127 \\
(.89)\end{array}$ \\
\hline College & $\begin{array}{c}1.354 \\
(2.47)\end{array}$ & $\begin{array}{r}-.102 \\
(.19)\end{array}$ \\
\hline Foreign & $\begin{array}{l}1.505 \\
(1.61)\end{array}$ & $\begin{array}{l}1.069 \\
(.87)\end{array}$ \\
\hline \multicolumn{3}{|l|}{ First occupation: } \\
\hline Clerical & $\begin{array}{r}-.091 \\
(.45)\end{array}$ & $\begin{array}{l}-.128 \\
(.54)\end{array}$ \\
\hline Telephone & $\begin{array}{l}.232 \\
(.74)\end{array}$ & $\begin{array}{l}.390 \\
. .94)\end{array}$ \\
\hline Professional & $\begin{array}{r}.278 \\
(1.00)\end{array}$ & $\begin{array}{r}-.137 \\
(.52)\end{array}$ \\
\hline Sales & $\begin{array}{l}-.290 \\
(1.27)\end{array}$ & $\begin{array}{l}-.274 \\
(1.07)\end{array}$ \\
\hline Manufacturing & $\begin{array}{l}-.533 \\
(2.83)\end{array}$ & $\begin{array}{l}-.538 \\
(2.34)\end{array}$ \\
\hline $\begin{array}{l}R^{2} \\
-2 \times \log \text { likelihood ratio }\end{array}$ & $1,494.4$ & .151 \\
\hline No. of observations & 1,247 & 1,247 \\
\hline
\end{tabular}

SotKCl:-1939 Retrospective Survey. See n. 16 above.

$\mathrm{NOTI}$ - Absolute values of $t$-statistics are given in parentheses under the coefficients. Education is measured in years; foreign = forcign educated, for which education is set equal to 0 ; the omitted occupation is a miscellaneous unskilled category, including domestics and waitresses; other, minor occupational dummies werc also included.

- Because PERCENT is 1 in $21 \%$ of the cases, the transformation suggested by Cox (Maddala 1983, p. 30) has been used: $\log [(p+1 / 2 n) /(1-p+1 / 2 n)]$. Appropriate weights have been applied.

of first occupation, independent of education and the age work began. Beginning in a manufacturing job reduced time spent in the work force by about 10 percentage points $(.25 \times .75 \times-.538)$ below that in professional and clerical jobs as well as those categorized as unskilled, assuming a mean of $25 \%$. Many of those who persisted in low paying jobs continued to work in their own homes, for example, as dressmakers.

The role of first occupation is important in understanding trends over time in the labor-force participation of women. The economy's jobs in the nineteenth century were dominated by those in the agricultural and man- 
ufacturing sectors, and women were frequently employed as domestics and factory operatives. The swift growth of the clerical sector in the early twentieth century greatly altered female employment. Occupations in manufacturing and the clerical sector differed in fundamental ways. Manufacturing jobs had earnings functions that rose rapidly with time on the job, but increased little with education, and reached an early plateau. There is evidence that earnings fell both with time away from the job and, more important, with age itself. The earnings function for clerical work rose less rapidly, rewarded formal training, and depreciated little with time away from the job and not at all with age. ${ }^{21}$

Thus it is not surprising that women who began in manufacturing positions exited from the labor force at an early age and those who began in professional and clerical jobs (but not necessarily sales, which put a premium on youth) persisted. The results provide further evidence that the evolution of married women's work may have required particular types of occupations and earnings functions. It is not clear, however, whether the characteristics of the initial occupation or unobservable differences among women, determining the choice of first occupation, were the ultimate cause.

The employment data in the 1939 Retrospective Survey primarily span the 1920 s and 1930s, and although labor-force participation rates of married women expanded during that time, the decades were not ones of impressive change. The 1950 s and 1960s witnessed more rapid increases in participation rates particularly among women older than 35 years, and the Social Security Administration's Retirement History Study is used to explore their laborforce attachment (see Irelan 1972; Mallen 1974; and Henretta and O'Rand 1980). It is important to realize that the survey was not meant to be a probability sample and that only wives of survey respondents are included. ${ }^{22}$ Further, and as mentioned previously, social security coverage varied over time and for certain jobs.

Despite these complications, the results of the analyses below will indicate conclusively that women in the labor force tended to remain employed during the 1950s and 1960s. Because these were times of rather large increases in participation rate of married women, this finding implies that recent entrants had little prior labor-force experience. Therefore, years of job experience for the working population may have fallen over these years, even though the experience of the entire female population must have risen.

${ }^{21}$ See Goldin (1984) for a detailed discussion of earnings functions in manufacturing and clerical work.

22 Certain restrictions are placed on the sample for comparability with other data sets. Only white, married women between the ages of 54 and 63 in 1969 who were the first wives of the male respondents have been selected. 
Table 4

Life-Cycle Labor-Force Participation of Married Women, 1951-69, for Cohorts Born, 1906-15

A. Distribution of Years Worked since 1951, for Women 54-63 Years Old in 1969

\begin{tabular}{ccc}
\hline $\begin{array}{c}\text { Years Worked } \\
\text { during 1951-69 }\end{array}$ & $\begin{array}{c}\text { Cohort Born } \\
1906-10(\%)\end{array}$ & $\begin{array}{c}\text { Cohort Born } \\
1911-15(\%)\end{array}$ \\
\hline 0 & 44.0 & 37.7 \\
$1<3$ & 19.7 & 10.2 \\
$3<5$ & 5.5 & 6.3 \\
$5<7$ & 5.5 & 6.5 \\
$7<9$ & 4.8 & 4.7 \\
$9<11$ & 4.0 & 4.7 \\
$11<13$ & 3.6 & 5.1 \\
$13<15$ & 5.6 & 5.9 \\
$15<17$ & 4.7 & 5.2 \\
$17<19$ & 5.4 & 4.6 \\
19 & 7.5 & 9.2 \\
No. of observations & 1,568 & 2,065 \\
\hline
\end{tabular}

B. Distribution of Years Worked since 1951, Conditional on Working in 1953, 1960, or 1965

\begin{tabular}{|c|c|c|c|c|c|c|}
\hline \multirow{2}{*}{$\begin{array}{l}\text { Years Worked during } \\
1951-1969\end{array}$} & \multicolumn{3}{|c|}{$\begin{array}{c}1906-10 \text { Cohort } \\
\text { (\% If Work = } 1 \text { in Year) }\end{array}$} & \multicolumn{3}{|c|}{$\begin{array}{c}1911-15 \text { Cohort } \\
\text { (\% If Work }=1 \text { in Year) }\end{array}$} \\
\hline & 1953 & 1960 & 1965 & 1953 & 1960 & 1965 \\
\hline $1<3$ & 1.8 & 1.0 & .8 & 2.1 & 1.3 & .8 \\
\hline $3<5$ & 9.1 & 1.4 & .8 & 5.2 & 3.1 & 1.4 \\
\hline $5<6$ & 5.1 & 4.1 & 8.4 & 7,8 & 3.2 & 6.7 \\
\hline $7<9$ & 7.8 & 4.1 & 6.3 & 6.2 & 3.9 & 7.2 \\
\hline $9<11$ & 6.3 & 7.5 & 8.1 & 6.2 & 7.2 & 8.6 \\
\hline $11<13$ & 6.3 & 9.5 & 6.9 & 6.1 & 12.3 & 10.9 \\
\hline $13<15$ & 9.1 & 17.0 & 13.2 & 8.4 & 15.8 & 12.9 \\
\hline $15<17$ & 6.3 & 14.0 & 14.5 & 9.6 & 14.2 & 13.2 \\
\hline $17<19$ & 18.7 & 17.0 & 17.1 & 14.8 & 12.4 & 12.5 \\
\hline 19 & 29.6 & 23.7 & 23.8 & 33.6 & 26.6 & 25.8 \\
\hline No. of observations & 396 & 494 & 491 & 562 & 710 & 734 \\
\hline
\end{tabular}

SourCE.-Retirement History Study-Social Security Administration exact match tapes (Irelan et al. 1987).

NOTE.-Work $=1$ is defined as $\geq 2$ quarters of (covered) paid employment during the year.

The distribution of years worked since 1951, given in table 4, part A, covers women who were between 54 and 63 years old in 1969 and 36 to 45 years old in 1951. Labor-market work in a year is defined as working in a covered occupation for at least two quarters, a definition necessarily differing from that used above but similar to that used in analyses of the NLS and PSID retrospective portions. ${ }^{23}$ The distribution of years worked is similar to both the NLS sample (Heckman and Willis 1979) and a laborforce weighted average of the 1939 data in table 1 . A substantial mass forms

${ }^{23}$ Labor-force participation rates from 1951 to 1969 calculated in this way for the cohort born 1906-1915 are similar to the actual rates achieved by the group, although those computed from the social security data have sharp breaks reflecting 
around 0 years, and a sudden upturn occurs at the maximum tenure possible, 19 years.

Distinctions between current workers and nonworkers become more apparent by conditioning the distribution on prior work experience. Working in either 1953,1960, or 1965 radically alters the distribution, as is apparent in table 4, part $\mathrm{B}$. Among women in the younger age cohort who worked in 1960 , about $70 \%$ would eventually work more than 13 of the total 19 years, that is, they would work $70 \%$ of the period 1951-69. Fully $48 \%$ of those in the older cohort who worked in 1953 would eventually work $90 \%$ of the years from 1951 to $1969 ; 41 \%$ of those working in 1965 would work $90 \%$ of these 19 years. But of those not working in $1960,85 \%$ would eventually work fewer than 5 years; $64 \%$ would not participate at all (defined as never working two quarters in any one year).

\section{Implications of Life-Cycle Labor-Force Participation in Theory and Practice}

Labor-market experience of working and nonworking married women can be computed directly from the labor-force histories in the 1939 Retrospective Survey, as is done in table 1, part B. Women employed in 1939 and $40-49$ years old had 15.5 years of job experience since beginning work, while those not in the labor force in 1939 had 7.6 years, less than half the time. The figures for the 30-39 year olds are absolutely lower but are higher as a percentage of years since beginning work, 12.2 years for those working in 1939 and 6.0 years for those not.

Life-cycle labor-force experiences for cohorts in other years can be computed indirectly, or inferred, from the data. The method used here is one of many that can be employed with incomplete data (see Smith and Ward [1984] for a different but related technique), but it is the only one that can be used with the limited information in the 1939 Retrospective Survey. Analytical expressions are derived for the average labor-market experience of working women in homogeneous and heterogeneous populations, and these expressions are then used to show how years of work experience respond to changes in labor-force participation rates. These analytical expressions are a function of only two parameters and labor-force weights. Together with the proportion of the population that is homogeneous, these equations yield estimates of work experience for cohorts and cross sections.

Two functions are needed in the analysis that follows: a labor-force participation rate function that varies with age for each cohort, $L(A)$, and the distribution of the population by age, $f(A)$. It will be assumed for simplicity that the two functions are stable over time and, therefore, that

amendments to the Social Security Act in 1951 and 1956. The computed rates should be somewhat lower than the official participation rates because social security coverage is incomplete, but the definition of participation imposed on the social security data necessarily inflates participation. 
$\%$ ir Labor Force

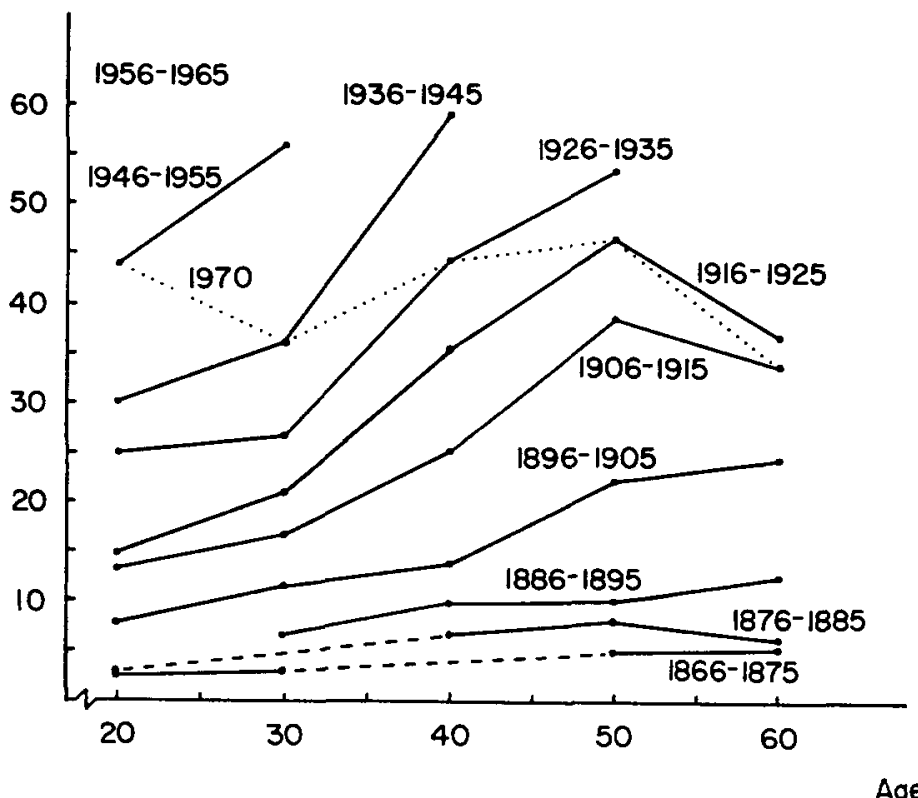

FiG. 1.-Labor-force participation rates of cohorts of white married women, born 1866 to 1965. Source.-Goldin (1983), derived from population census data. Observations are the midpoints of five age groups: 15-24, 25-34, 35-44, 45-54, and 55-64. Dashed lines denote missing data. Data from 1890 to 1920 are for native-born women with native-born parents.

Dotted line is the 1970 cross section.

cross-section and cohort functions are the same. The empirical work below relaxes this assumption.

The actual relationship between labor-force participation and age must first be examined. Participation rates for cohorts of married white women in the United States born from 1855 to 1965 have risen with age, as can be seen from the solid (and dashed) lines in figure 1.24 Each and every cohort has had rising labor-force participation rates within its married lifetime. ${ }^{25}$ In contrast, cross-section participation rates for married white

${ }^{24}$ These results are virtually unaffected by adjustments for urbanization and reflect the extraordinary increases over time in the participation rates of adult women. See Goldin (1983).

${ }^{25}$ Three qualifications must be added. First, all cohorts have higher labor-force participation rates when single than when married. Second, finer age breakdowns would indicate some drop in participation among various cohorts in the youngest age groups shown. Third, work experience during World War II cannot be included in the diagram because labor-force data for the 1940 s are not disaggregated by marital status and race. It seems clear, however, that many older married women in the labor force in 1950 were working in the 1940s. They, therefore, returned to the labor force with more job experience than my measures will indicate. 
women decline with age before 1950 and have had a bimodal shape for the period after (the dotted line in fig. 1 gives 1970 data). Assume, therefore, that cohort labor-force participation $(0 \leq L \leq 1)$ rises with age $(A)$ in some linear fashion, as has been the case for cohorts of white married women, such that

$$
L(A)=\alpha+\beta A, \quad \beta>0 .
$$

Thus the graph of equation (1) in figure 2 is a schematic representation of the cohort lines in figure 1.

The labor-force participation rate function, $L(A)$, will be used to compute years of work experience among two distinct populations, homogeneous and heterogeneous women, in the following intuitive manner. Consider first the case of homogeneous women. Assume that women, at each age, spend $L(A)$ fraction of the year in the labor force, and all are present in the labor force for the same proportion of each year. Therefore, the total number of years each is in the labor force over her lifetime is the sum of the labor force rates, or the integral of $L(A)$. Alternatively, in the case of

\section{$\%$ in Labor Force}

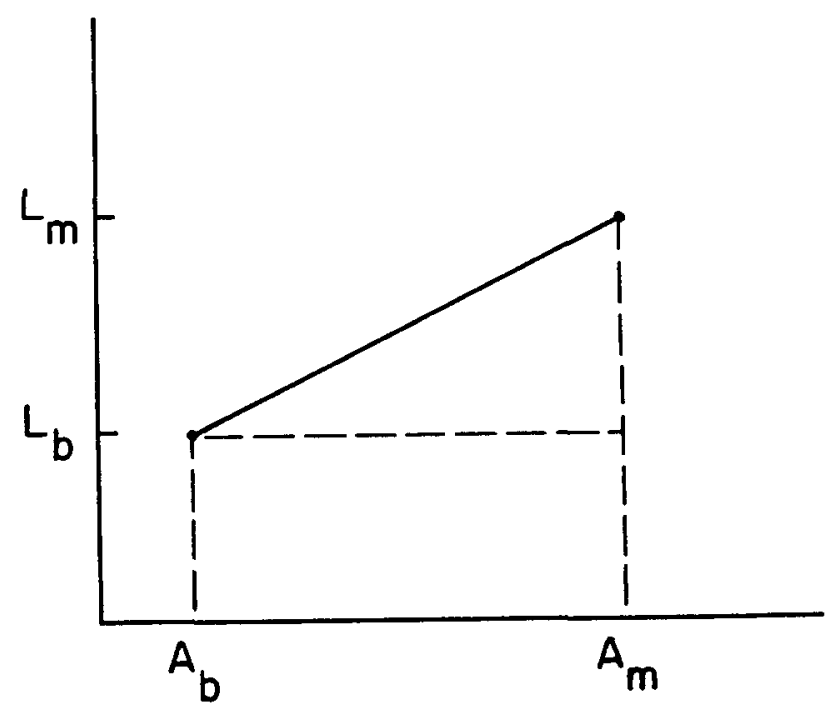

FIG. 2.-The labor-force participation rate function 
all heterogeneous women, increased participation with age implies that women who were out of the labor force at $A_{b}$ in figure 2, for example, must enter for any $A>A_{b}$. As the labor-force rate increases, new workers must be drawn into the labor force while all old workers remain employed. The maximum number of workers are employed at $A_{m}$, when the laborforce participation rate is $L_{m}$. A woman who is in the labor force at $A_{b}$, therefore, accumulates $\left(A_{m}-A_{b}\right)$ years of experience over her lifetime; one who enters at $\left(A_{b}+1\right)$ accumulates $\left(A_{m}-A_{b}-1\right)$ years, and so on. Thus average years of work experience of this cohort at the end of its working life is, once again, the integral of $L(A)$, but now divided by $L_{m}$. The integral must be divided by the maximum percentage who are ever in the labor force, just as an integral of years experience would have to be divided by the number of women ever in the labor force. In the homogeneous case, all are in the labor force and no division is necessary. A limiting case is instructive. If $\beta=0$, and $L(A)$ were horizontal at $L_{b}$, the integral from $A_{b}$ to $A_{m}$ would be $L_{b} \times\left(A_{m}-A_{b}\right)$, which must be divided by $L_{b}$ to get mean years experience for a cohort that worked each year.

Work experience in the heterogeneous case must always be greater than work experience in the homogeneous case for a given $L(A)$, as long as $L(A)<1$. Further, as the $L(A)$ function becomes steeper, $(d \beta>0)$, mean work experience in the heterogeneous case must decrease, while that in the homogeneous case must increase. Work experience in the homogeneous case must increase because all individuals work more weeks per year, but it must decrease in the heterogeneous case because less experienced workers are added to the working group. Returning to the limiting case, if $\beta=0$, then work experience at $A_{m}$ would be the maximum possible, $\left(A_{m}-A_{b}\right)$ for each worker. By adding just one more worker at any point after $A_{b}$, mean lifetime work experience of the cohort will decrease. The marginal worker, whose work experience is below the average, must bring down the average. To get work experience for a cross section, under either assumption, all cohorts must be aggregated by weighting each by its share in the working population. The empirical demands of the procedure are few: the two parameters of the cohort labor-force participation function, the weights for aggregating the cohorts, and the proportion in each of the groups. A formal presentation of the two cases follows.

The first case is that of a cohort of homogeneous women, all of whom have the same probability of being captured in the labor force in a particular year. If $A_{b}$ is the age at which work begins and $A_{n}$ is the present age of the cohort ( $<A_{m}$, the age at which work terminates for the cohort), then the following expression gives years of work experience (EXP) for an average working woman of age $A_{n}$ in the homogeneous case:

$$
\operatorname{EXP}\left(A_{n}\right)=\int_{A_{b}}^{A_{n}}(\alpha+\beta A) d A
$$


Average years of accumulated experience for each cohort is given by the integral of the labor-force participation rate function from $A_{b}$ to $A_{n}$.

In any one year, mean experience of a cross section of cohorts whose members are homogeneous, (EXP*), is derived by weighting the average work experience of each cohort, equation (2), by the age distribution of the working population, $f_{w}(A),{ }^{26}$

$$
\operatorname{EXP}^{*}=\int_{A_{b}}^{A_{m}} \operatorname{EXP}\left(A_{n}\right) f_{w}\left(A_{n}\right) d A_{n} .
$$

where an asterisk $\left({ }^{*}\right)$ denotes a cross section of cohorts, rather than a specific cohort. The age distribution of the working population, $f_{w}(A)$, is equal to $\left\{[f(A)(\alpha+\beta A)] / L_{t}\right\}$, where the population density function is $f(A),{ }^{27}$ such that

$$
\int_{A_{b}}^{A_{m}} f(A) d A=1
$$

and the female labor-force participation rate for the entire population is the weighted average:

$$
L_{t}=\int_{A_{b}}^{A_{m}}(\alpha+\beta A) f(A) d A .
$$

Intuitively, one wants the experience of all cohorts in the cross section, $\left[\operatorname{EXP}\left(A_{n}\right), n=b, \ldots, m\right]$, weighted by each cohort's contribution to the working population, $f_{w}\left(A_{n}\right)$. The weight of each cohort depends on both its proportion in the population and its participation rate.

Consider, instead, a cohort of heterogeneous women, whose members have different probabilities of being in the labor force. The average accumulated work experience (EXP', where a prime denotes the heterogeneous case) for a working woman at age $A_{n}$ is given by

$$
\operatorname{EXP}^{\prime}\left(A_{n}\right)=\int_{A_{b}}^{A_{n}}(\alpha+\beta A) d A /\left(\alpha+\beta A_{n}\right) \text {. }
$$

It is, once again, the sum of the labor-force participation rates but now divided by the highest participation rate currently achieved by the cohort.

${ }^{26}$ For example, in the homogeneous case, if all women die after $A_{m}$ and the population were stationary, i.e., $f(A)$ is uniform, then $\operatorname{EXP}^{*}=(\operatorname{EXP} / 2)$.

${ }^{27}$ The age distributions of the various cohorts and cross sections will differ if the population is not stable. 
In the heterogeneous case, with a cohort participation schedule given by equation (1), only those currently in the labor force can accumulate experience. Dividing by $\left(\alpha+\beta A_{n}\right)$ allocates the accumulated experience only to those who were in the labor force at some point in the past. Thus the relationship between the homogeneous and heterogeneous cases is EXP' $=\operatorname{EXP} / L_{n}$, where $L_{n}=\left(\alpha+\beta A_{n}\right)$. In the heterogeneous case only $L_{n}$ fraction of the female population had ever been employed, and $\left(1-L_{n}\right)$ had never been employed over the life cycle.

Mean experience for the cross section is again obtained by integrating over the working population and weighting by the age distribution of the working population. Mean work experience of a cross section of heterogeneous, currently working women is given by

$$
\operatorname{EXP}^{* \prime}=\int_{A_{b}}^{A_{m}} \operatorname{EXP}\left(A_{n}\right)\left[f\left(A_{n}\right) / L_{t}\right] d A_{n}
$$

where $\operatorname{EXP}\left(A_{n}\right)$, from equation (2), is the experience of a homogeneous cohort of age $A_{n}$. The difference between equations $\left(2^{\prime}\right)$ and $\left(3^{\prime}\right)$ provides the intuition for the heterogeneous case. The experience of the heterogeneous cohort is $\operatorname{EXP}^{\prime}=\operatorname{EXP} /\left(\alpha+\beta A_{n}\right)$. Substitute it in (2') and multiply by the age distribution of the working population, $f\left(A_{n}\right)\left(\alpha+\beta A_{n}\right) / L_{i}$; then cancel terms to yield ( $\left.3^{\prime}\right)$.

The following propositions hold even when labor-force participation rates are identical between two worlds of homogeneous and heterogeneous women.

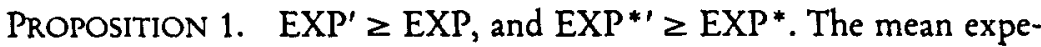
rience of both cohorts and cross sections of working women will be greater in the heterogeneous case unless $L_{n}=1$.

PROPOSITION 2. $\partial \mathrm{EXP} / \partial \beta>0$, but $\partial \mathrm{EXP}^{\prime} / \partial \beta<0$. Increasing the gradient of the labor-force participation schedule with respect to age will always increase experience of the cohort in the homogeneous case, but will reduce average experience in the heterogeneous case.

PROPOSITION 3. $\partial \mathrm{EXP} / \partial \alpha>0$ and $\partial \mathrm{EXP}^{\prime} / \partial \alpha \geq 0$. Increasing the intercept will increase experience for the cohort except in the heterogeneous case with $\beta=0$.

The implications of these results for the ratio of female to males wages are straightforward if productivity and occupational choice are determined solely by expected number of years in the labor force. ${ }^{28}$ For the same configuration of labor-force participation rates by age, wages should be

${ }^{28}$ The simplest way to view the relationship between years of work experience and the ratio of female to male earnings is to assume, as a first approximation, that the wage equations for both men and women are linear in the logs of experience and other variables, such as schooling. 
higher in the heterogeneous case because EXP' $\geq$ EXP. If, however, laborforce participation rates are increasing over time, particularly with $\partial \beta / \partial t$ $>0$, although possibly even with $\partial \alpha / \partial t>0$, wages can decrease in the heterogeneous case while rising in the homogeneous case. Further complications can be added if the length of breaks in participation also determines wages and occupations. The implication regarding wages is then ambiguous and would depend on the degree to which labor-market training depreciated with time away from the labor force. If depreciation were exponential in time, women in the homogeneous case who enter and exit with much frequency would retain more human capital than would those in the heterogeneous case whose gaps in participation are much greater.

Because direct estimates of work experience can be computed from the 1939 Retrospective Survey for only a few cohorts, the expressions in equations $\left(2^{\prime}\right)$ and $\left(3^{\prime}\right)$ are used to produce estimates for various age groups from 1900 to 1980 for cohorts of married women born from 1875 to 1925 . The procedure used relies on various assumptions to produce estimates that are consistent with those directly computable from the 1939 and social security data. Some fraction of the female population and the female labor force will be termed homogeneous, and one minus the fraction will be heterogeneous. The expressions in (2) and (3) will be used to produce estimates of the average work experience of these two groups separately, and the aggregation and weighting procedure is given by $\left(2^{\prime}\right)$ and $\left(3^{\prime}\right)$. All that is needed, other than the population and labor-force weights and the proportion homogeneous, are the parameters $\alpha$ and $\beta$ from the cohort labor-force equations. These have been estimated from the data underlying figure 1 , and are given in the right-hand portion of table 5.

Cohort labor-force participation rates for women born around 1895, and thus 40-49 years old in 1939, for example, imply from figure 1 an $\alpha$ of about 0.02 and a $\beta$ of about 0.0027 , the two parameters of equation (1). Equations (2) and (3), which are functions of these two parameters alone, yield values of $\mathrm{EXP}=2.7$ years and $\mathrm{EXP}^{\prime}=19.0$ years for the homogeneous and heterogeneous cases, respectively $\left(A_{b}=20\right.$ and $\left.A_{n}=45\right)$. Actual labormarket experience for this cohort, 15.5 years, is considerably closer to the perfectly heterogeneous than the perfectly homogeneous case, consistent with the evidence on life-cycle labor-force participation of current participants in table $1 .^{29}$

The homogeneous and heterogeneous groups are extreme cases, and reality can be conceptualized as some mixture of the two. Thus the construction of aggregate years of experience requires an assumption about their distribution within the working (and total) population. A hetero-

\footnotetext{
${ }^{29}$ Note that the actual value is for the Cleveland data, but the computed values are implicitly for the entire United States. Differences in participation for married women by level of urbanization will affect such comparisons.
} 
Table 5

Simulated Years of Work Experience since Marriage for Cohorts of Working Married Women, 1900-1980

\begin{tabular}{|c|c|c|c|c|c|c|}
\hline & \multicolumn{4}{|c|}{ Age } & \multicolumn{2}{|c|}{$\begin{array}{l}\text { Parameter } \\
\text { Values }\end{array}$} \\
\hline & $20-29$ & $30-39$ & $40-49$ & $50-59$ & $a$ & $\beta$ \\
\hline \multirow[t]{3}{*}{$\begin{array}{c}\text { Cohort b } \\
1875 \\
1885 \\
1895 \\
1905 \\
1915 \\
1925\end{array}$} & $\begin{array}{l}3.63 \\
3.73 \\
3.77 \\
3.79 \\
3.82 \\
3.85\end{array}$ & $\begin{array}{r}9.53 \\
9.98 \\
10.16 \\
10.16 \\
10.25 \\
10.36\end{array}$ & $\begin{array}{l}13.78 \\
14.56 \\
14.95 \\
15.10 \\
15.38 \\
15.69\end{array}$ & $\begin{array}{l}16.06 \\
17.11 \\
17.86 \\
18.50 \\
19.29 \\
20.04\end{array}$ & $\begin{array}{l}.00 \\
.01 \\
.02 \\
.02 \\
.02 \\
.02\end{array}$ & $\begin{array}{l}.0012 \\
.0016 \\
.0027 \\
.0049 \\
.0069 \\
.0087\end{array}$ \\
\hline & \multicolumn{4}{|c|}{ Age } & \multirow{2}{*}{\multicolumn{2}{|c|}{$\begin{array}{l}\text { Weighted } \\
\text { Average* }\end{array}$}} \\
\hline & $20-29$ & $30-39$ & $40-49$ & $50-59$ & & \\
\hline $\begin{array}{l}\text { Year: } \\
1930 \\
1940 \\
1950\end{array}$ & $\begin{array}{l}3.79 \\
3.82 \\
3.85\end{array}$ & $\begin{array}{l}10.16 \\
10.16 \\
10.25\end{array}$ & $\begin{array}{l}14.56 \\
14.95 \\
15.10\end{array}$ & $\begin{array}{l}16.06 \\
17.11 \\
17.86\end{array}$ & & $\begin{array}{l}11 \\
88 \\
52\end{array}$ \\
\hline
\end{tabular}

SOURCE. -1939 Retrospective Survey. See n. 16 above.

NoTE.-The homogeneous and heterogeneous cases are computed from equations (2) and (3), assuming $A_{b}=20$ years (that is the mean age at first marriage is 20 years), and $A_{n}=$ the mean of the age group; from equation (2), EXP $=\alpha\left(A_{n}-A_{b}\right)+(\beta / 2)\left(A_{n}^{2}-A^{2}\right)$, and from equation (3), EXP' $=\operatorname{EXP} /\left(\alpha+\beta A_{n}\right)$. The parameters $\alpha$ and $\beta$ are computed from data underlying figure 1. The computation of total work experience assumes that the percentage of women who are heterogeneous by age is given by those working $65 \%$ or more of the years since beginning work or from the data underlying table 1: 20-29 years $80 \%$; $30-39$ years $80 \% ; 40-49$ years $75 \%$; and $50-59$ years $65 \%$.

- The weights used are:

Age Distribution of Married (White) Working Women

\begin{tabular}{llll}
\hline Age & 1930 & 1940 & 1950 \\
\hline $20-29$ & .38 & .32 & .29 \\
$30-39$ & .34 & .36 & .34 \\
$40-49$ & .19 & .22 & .25 \\
$50-59$ & .09 & .10 & .12 \\
\hline
\end{tabular}

geneous individual is defined here as one who has spent more than $65 \%$ of her years since beginning work in the labor force..$^{30}$ Using this definition, the data underlying table 1 indicate that $75 \%$ of the women $40-49$ years old were heterogeneous. A weighted average of the two work experience numbers for the cohort born in 1895 is 14.95 years, reasonably close to the actual one of 15.5 , considering that the latter includes years worked before marriage. The homogeneous and heterogeneous work experience

${ }^{30}$ The value of $65 \%$ is somewhat arbitrary, and was chosen because it reproduces the actual data rather well. If, by heterogeneity, one means remaining in the labor force since work began, the value would be $100 \%$. Note that those not in the labor force in 1939 are excluded from those in at least $65 \%$ of the time since work began. If those not currently in the labor force were truly homogeneous in their labor supply, then the probability any would fall in that range is extremely low. 
numbers for the 30-39-year-old cohort born in 1905 are 2.7 and 14.2 respectively, given $\alpha=0.02$ and $\beta=0.0049$. The weighted average, once again using the definition of heterogeneity as more than $65 \%$, is 10.16 , roughly comparable to the actual figure of 12.2 , again considering the average number of years worked before marriage.

Labor-market experience since marriage for all cohorts of women born from 1875 to 1925 can be estimated using this technique across the years 1900-1980, as has been done in table 5. The two parameters of the laborforce equation ( $\alpha$ and $\beta$ ) have been approximated from the data underlying figure 1; the heterogeneous proportion of the current labor force at each age, assumed to be stable over time, is given by the 1939 data (which are consistent with the social security data).

Years of experience simulated in this manner for currently working married women increase only slightly over this long time period despite substantial gains in labor-force participation (see table 5). For 40-49-yearolds, years of work experience accumulate at $.41 \%$ per year from 1920 to 1940 and at only $0.16 \%$ per year from 1940 to 1970 . Across the entire $50-$ year period the increase for this age group is from 13.8 years to just 15.7 years, and increases for the other age groups are comparable. In the 1950s, when female labor-force participation expanded rapidly, years of experience increased by the smallest percentage, this primarily due to the increase in $\beta$ (the slope of the cohort labor-force participation rate function) and the substantial proportion of women with heterogeneous labor supply. Years of work experience for the heterogeneous component alone frequently decreased during the decades when $\beta$ increased (it would have to if $\alpha$ were constant). Average work experience for 40-49-year-olds increased over the 30-year period 1940-1970, but only because that for the homogeneous component did.

Aggregate years of experience for the entire population of working women can be obtained by weighting the figures in the lower part of table 5 by the age distribution of the female labor force, as in equations $\left(2^{\prime}\right)$ and $\left(3^{\prime}\right)$. The aging of the female labor force over the period caused aggregate years of experience to increase somewhat more than the separate entries do by age. It rose from 9.11 in 1930 , the first year for which all age groups appear in table 5, to 9.88 in 1940, and reached 10.52 in 1950, the last year for which all age groups appear (see bottom of table 5). These results are consistent with those of Smith and Ward (1984) who estimate life-cycle labor-force participation by a different indirect procedure. ${ }^{31}$ According to

${ }^{31}$ The procedure used by Smith and Ward (1984) assumes three groups in the population: $S_{w}=\%$ of the population who stay in the labor force; $S_{n}=\%$ of the population who remain out of the labor force; and $\left(1-S_{n}-S_{n}\right)$ who move according to a 2-state Markov model. In my model, the fraction who are homogeneous move in and out, and the fraction who are heterogeneous are either in the labor force or move in as the aggregate participation rate increases. 
their estimates, work experience of employed, 40-year-old women remained roughly constant at 13.5 years from 1940 to 1980 , while the work experience of the entire population of women age 40 rose by more than 4 years. ${ }^{32}$ Years of work experience across all working women was 11.57 in 1950, 13.25 in $1960,12.97$ in 1970 , and 12.22 in $1980 .^{33}$

Various implications for historical aspects of "wage discrimination" are contained in this and related research. The ratio of female to male (fulltime) earnings remained virtually stable at about .60 during the $1950-1980$ period (O'Neill 1985). My estimates of work experience for 1950 to 1980 support those of Smith and Ward (1984), who find little increase among cross sections of employed women. Therefore, the increase in female laborforce participation and the constancy of the ratio of female to male earnings since 1950 are not inconsistent findings. I have elsewhere reported that the ratio of female to male (full-time) earnings was not constant during the first half of this century, but rose from about .46 in 1890-1900 to just below .60 by 1940 (Goldin 1987). Even though years of work experience increased little among employed married women, older and married women greatly increased their share of the female labor force over the first half of this century. The average work experience of the entire female labor force expanded from about 6 or 7 years around 1900 to almost 11 years by $19400^{34}$ Increased years of work experience from 1900 to 1940 explains about half the increase in the ratio of female to male earnings over the period (Goldin and Polachek [1987] contains a complete partitioning for 1900-1970).

Because married women tend to remain in the labor force, they accumulate considerable work experience, and thus their low earnings in comparison with those of men are less explicable. I find, for example, in a study of clerical workers in 1940 , that less than $50 \%$ of the difference in

${ }^{32}$ In comparison, a simple average of the columns in table 5 for the 30-39 and 40-49 age groups yields average years work experience for employed 40-year-old women that begins at 11.88 years in 1920 , increases in 12.56 years by 1940 , and then increases gradually to 12.87 to 1960 . The work experience of the entire population of women can also be constructed using the procedure underlying table 5 , under the assumption that the heterogeneous and homogeneous distinction also applies to the entire population of women.

${ }_{33}^{3}$ These data are computed from material in Smith and Ward (1984); see n. 3 above. Much of the increase from 1950 to 1960 and the subsequent decrease in work experience are caused by changes in the age distribution of the employed population of women.

4 Years of work experience in 1900 is derived from various cross-section studies of working women (see Goldin and Polachek 1987); that for 1940 is a direct estimate from the 1939 Retrospective Survey, which also included single, widowed, and divorced women, weighted by the national labor-force proportions in 1940. 
the log of earnings can be explained by differences in attributes between men and women; similar estimates have been uncovered with more modern data. One possible reason for "wage discrimination," as it is termed, has been revealed in the 1939 Retrospective Survey. More than $80 \%$ of all women who began work before marriage (and who were about 45 years old in 1939) dropped out of the labor force at the precise time of marriage. Those who remained in the labor force or later reentered persisted for long periods of time, but employers may have channeled young women into dead-end, low-paying jobs. Employers may not have been able to ascertain who would persist, and "statistical discrimination" may have played a large role.

In sum, the two data sets giving life-cycle labor-force histories for cohorts of women born from the 1880 s to the 1910 s indicate substantial (unconditional) heterogeneity in labor-force participation. Married women in the labor force tend to remain in and are joined by others whose entry expands the labor-force participation rate. An exploration of the determinants of labor-force persistence points to the importance of early occupational choice, with women who began in manufacturing jobs tending to exit the labor force on marriage. The substantial heterogeneity of labor-force participation means that accumulated work experience of currently employed married women barely increased during periods of rising labor-force participation. The relative stability in years of experience for the working population of married women suggests that the steadiness of the ratio of female to male wages since 1950 is not inconsistent with the increase in female labor-force participation over that time period. But it also implies that years of work experience among married women was considerable and that "wage discrimination" was and is substantial.

\section{References}

Ben-Porath, Yoram. "Labor-Force Participation Rates and the Supply of Labor." Joumal of Political Economy 81 (May/June 1973): 697-704.

Goldin, Claudia. "The Changing Economic Role of Women: A Quantitative Approach." Journal of Interdisciplinary History 14 (Spring 1983): 707-33.

- "The Historical Evolution of Female Earnings Functions and Occupations." Explorations in Economic History 21 (January 1984): 1-27.

- "The Female Labor Force and American Economic Growth, 18901980." In Long-Term Factors in the American Economic Growth, edited by Stanley L. Engerman and Robert E. Gallman, pp. 557-604. Chicago: University of Chicago Press, 1986.

"The Gender Gap in Historical Perspective." In Quantity and Quiddity: Essays in U.S. Economic History, edited by Peter Kilby, pp. 135-70. Middletown, Conn.: Wesleyan University Press, 1987.

- "Marriage Bars: Discrimination against Married Women Workers, 1920 's to 1950 's." NBER working paper. Cambridge, Mass.: NBER, 1988 , in press. 
Goldin, Claudia, and Polachek, Solomon. "Residual Differences by Sex: Perspectives on the Gender Gap in Earnings." American Economic Review 77 (May 1987): 143-51.

Heckman, James J., and Willis, Robert J. "A Beta-logistic Model for the Analysis of Sequential Labor Force Participation by Married Women." Journal of Political Economy 85 (February 1977): 27-58.

- "Reply to Mincer and Ofek." Joumal of Political Economy 87 (February 1979): 203-12.

Henretta, John C., and O'Rand, Angela M. "Labor-Force Participation of Older Married Women." Social Security Bulletin 43 (August 1980): 1016.

Irelan, Lola M. "Retirement History Study: Introduction." Social Security Bulletin 35 (November 1972): 3-8.

Irelan, Lola M.; Rabin, William; and Schwab, Karen. SSA's Retirement History Study: Technical Description. Social Security Administration Publication no. 13-11783. Washington, D.C.: U.S. Department of Health and Human Services, September 1987.

Maddala, G. S. Limited-dependent and Qualitative Variables in Econometrics. New York: Cambridge University Press, 1983.

Mallen, Lucy. "Women Born in the Early 1900s: Employment, Earnings, and Benefit Levels." Social Security Bulletin 37 (March 1974): 3-24.

Mincer, Jacob. "Labor Force Participation of Married Women." In Aspects of Labor Economics, edited by H. Gregg Lewis. Universities-National Bureau Conference Series no. 14, pp. 63-97. Princeton, N.J.: Princeton University Press (for NBER), 1962.

- "Labor Force Participation and Unemployment: A Review of Recent Evidence." In Prosperity and Unemployment, edited by R. A. Gordon and M. S. Gordon, pp. 73-112. New York: Wiley, 1966.

Mincer, Jacob, and Ofek, Haim. "The Distribution of Lifetime Labor Force Participation of Married Women: Comment." Joumal of Political Economy 87 (February 1979): 197-201.

Moulton, Brent R. "Human Capital Accumulation and Trends in the MaleFemale Wage Gap in the United States, 1956-1983." Unpublished working paper. U.S. Bureau of Labor Statistics, Washington, D.C., March 1986.

O'Neill, June. "The Trend in the Male-Female Wage Gap in the United States." Journal of Labor Economics 3, suppl. (January 1985): S91-S116.

Ruggles, Nancy D., and Ruggles, Richard. "The Anatomy of Earnings Behavior." In The Distribution of Economic Well-Being, edited by F. Thomas Juster, pp. 115-58. New York: NBER, 1977.

Smith, James P., and Ward, Michael P. Women's Wages and Work in the Twentieth Century. Santa Monica, Calif.: Rand, 1984.

U.S. Department of Labor, Women's Bureau. "Women Workers in Their Family Environment." Women's Bureau Bulletin no. 183. Washington, D.C.: U.S. Government Printing Office, 1941. 